\title{
Frontières
}

\section{Où est la marge et pourquoi la marge ?}

\section{Anne Claire Poirier}

Volume 14, numéro 1, automne 2001

Où est la marge ?

URI : https://id.erudit.org/iderudit/1074143ar

DOI : https://doi.org/10.7202/1074143ar

Aller au sommaire du numéro

Éditeur(s)

Université du Québec à Montréal

ISSN

1180-3479 (imprimé)

1916-0976 (numérique)

Découvrir la revue

Citer ce document

Poirier, A. C. (2001). Où est la marge et pourquoi la marge ? Frontières, 14(1),

5-5. https://doi.org/10.7202/1074143ar d'utilisation que vous pouvez consulter en ligne.

https://apropos.erudit.org/fr/usagers/politique-dutilisation/ 


\section{OU่ EST LA MARGE ET \\ POURQUOI LA MARGE?}

Anne Claire Poirier, Co-responsable du thème.

Nous avons souvent tendance à associer trop exclusivement la marge à l'itinérance, cette marge visible, troublante et dérangeante que l'on peut regarder tous les jours avec un certain apitoiement mais rarement avec compassion.

L'itinérance est l'effet d'une marginalisation rarement volontaire provoquée par l'irresponsabilité et l'intolérance face à la différence. De cette marge imposée qui se vit dans la rue, nous devons parler et en nommer les causes : la folie, la pauvreté, la maladie, la toxicomanie, la prostitution... Ces états différents qui menacent le confort psychologique de la majorité pas toujours silencieuse.

La marge active n'est pas un lieu physique, c'est un état intérieur. Il suppose un choix, un écart possible dans l'évaluation d'un risque. Refuser la marge, ce serait refuser le risque du changement et de la création. On ne prépare pas la révolution dans la sécurité de la norme ! L'évolution de l'art, de la philosophie, de la pensée politique, de la science, de la technologie... bref, l'histoire de l'humanité s'est vécue dans le risque de la marge. C'est de cette marge active, choisie, volontaire et essentielle dont il faudrait surtout parler. Elle provoque, tout autant que la première, la crainte, l'intolérance.

Je ne sens pas la nécessité de vous présenter les articles de ce numéro et leurs auteurs, ils se présentent très bien eux-mêmes avec conviction et intelligence. Leurs réflexions, recherches et points de vue sauront éclairer votre propre questionnement sur «OÙ est la marge ? » car cette question s'adresse à chacun d'entre vous et vous êtes seuls à pouvoir y répondre.

Le caractère essentiellement subjectif de la notion de marge nous renvoie obligatoirement à nous-mêmes, à notre capacité de tolérance autant qu'à ses limites. La marge n'est pas la même pour tous, celle que nous choisissons nous définit et nous ressemble. Elle est riche et complexe, porteuse de doutes et de révélations.

Je n'ai pas de réponse absolue au « OÙ ». Je continue quotidiennement ma quête. Je choisis la compassion. J'accepte l'inconfort du doute.

Je tenterai de répondre à la question : POURQUOI ?

Pourquoi la marge dans Frontières, une revue d'information et de recherches sur la mort?

Parce que la mort est le geste ultime d'un vivant et parce qu'il n'y a pas que la mort qui tue!

On ne meurt pas nécessairement dans un lit.

On meurt partout, on meurt à tout.

La mort ne se manifeste pas uniquement par l'interruption des battements cardiaques et de la respiration.
Il y a la mort de l'imaginaire, du désir, de la tolérance et de la justice.

La mort de l'amour!

Des morts causées par le refus du risque et la soumission trop servile à la norme endormeuse.

Comment survivre à ces morts ? Comment éviter de mourir vivant?

En prenant le risque de l'émergence.

Sortir de la certitude confortable, oser chercher en marge une zone inconnue, l'oasis vivifiant auquel on ne croyait plus.

La marge est une frontière.

Une frontière entre la norme et l'interdit mais aussi une frontière entre la sagesse et le délire, entre l'intolérance et le respect, entre l'intérêt et l'engagement, entre la certitude et le doute !

Les frontières sont des limites pour certains, des rêves ou des défis pour d'autres.

Demander le rapport entre la marge et la mort serait une question réductrice et futile.

La mort ne se conçoit que dans son rapport à la vie avec son organisation sociale, culturelle, économique et politique.

La revue Frontières invite ses lecteurs à parcourir un itinéraire élargi.

Si la mort vous intéresse, sortez des hôpitaux et des chambres à coucher et descendez dans la rue où la mort règne, solitaire et sournoise...

La marge est un lieu dangereux et fragile, mais c'est aussi un lieu de dépassement et d'exigence.

Nombreux sont ceux qui l'acceptent et la choisissent pour des raisons multiples et souvent opposées.

En proposant le thème de la marge au comité de rédaction, je faisais le rêve de pénétrer une zone interdite en prenant le risque de traverser certaines frontières. Nos collaborateurs ont percé quelques brèches dans la forteresse de la normalité et je les en remercie.

La réalité atteint rarement le rêve.

Il y a eu les inévitables imprévus, les impondérables, des désistements explicables.... Mais il y a eu aussi certains relents de censure sournoise, un excès de respect de l'autorité et une rigidité craintive devant certains sujets «à risque ». J'ai partagé avec Lise Lalonde, à qui ce numéro doit beaucoup, des moments d'enthousiasme exaltants et certaines déceptions devant une rectitude qui s'accorde mal avec le rêve des zones frontières.

Je remercie l'équipe de Frontières et je tiens à souligner l'importance du soutien constant et efficace de sa rédactrice en chef, Diane Laflamme.

Un gros merci au talent de Jacques Leduc qui offre généreusement à ce numéro un regard respectueux et sensible sur la marge. 